\title{
Experimental Investigation of Process Forces and Part Quality for Fine Blanking of Stainless Steel with Inductive Heating
}

\author{
Ingo Felix Weiser, Robby Mannens, Andreas Feuerhack and Thomas Bergs
}

Ingo Felix Weiser. Laboratory for Machine Tools and Production Engineering WZL of RWTH Aachen University, Campus-

Boulevard 30, D-52074 Aachen, Germany

Corresponding author: i.weiser@wzl.rwth-aachen.de

Robby Mannens. Laboratory for Machine Tools and Production Engineering WZL of RWTH Aachen University, Campus-Boulevard 30, D-52074 Aachen, Germany

Andreas Feuerhack. Laboratory for Machine Tools and Production Engineering WZL of RWTH Aachen University, CampusBoulevard 30, D-52074 Aachen, Germany

Thomas Bergs. Laboratory for Machine Tools and Production Engineering WZL of RWTH Aachen University, Campus-Boulevard 30, D-52074 Aachen, Germany

Fraunhofer-Institute for Production Technology IPT, Steinbachstr. 17, D-52074 Aachen, Germany

Abstract. Fine blanking is a highly productive process of industrial mass production with which high quality components in particular but not exclusively for the automotive industry are produced. The manufacturing process faces its limits at elevated tensile strengths of the materials to be processed. Consequently, high-strength steels can currently only be fine blanked to a limited extent. This can be overcome by lowering the flow stress of high-strength steels by means of inductive heating. A steel of high importance especially for industries with high hygiene standards such as medical and nutrition production is the stainless steel X5CrNi18-10 (1.4301). As a metastable austenitic steel which can initiate cutting impact on the press through martensitization, fine blanking of stainless steel is a challenge. X5CrNi18-10 is not a high-strength steel per se but becomes difficult to process due to the high hardness of the martensite phase, known as transformation-induced plasticity (TRIP) effect. Thus, in order to combine the possible advantages of the fine blanking process with inductive heating and the important properties of stainless steel, fine blanking of this steel was investigated with inductive heating prior to the fine blanking. The process forces and product quality properties such as die roll were investigated and found to be advantageous in comparison to non-heated fine blanking specimens of the same steel. The process forces and the die roll height decreased due to the heating.

Keywords. Sheet Metal Forming, Fine Blanking, Inductive Heating, Stainless Steel

\begin{tabular}{|ll|}
\hline Nomenclature \\
$h_{\mathrm{B}}$ & Burr height \\
$h_{\mathrm{dr}}$ & Die roll height \\
$h_{\mathrm{f}}$ & Height of fracture \\
$h_{\mathrm{s}}$ & Height of smooth cut \\
$s$ & Sheet thickness \\
$t$ & Time \\
$v_{\mathrm{c}}$ & Cutting velocity \\
$w_{\mathrm{B}}$ & Burr weight \\
$w_{\mathrm{dr}}$ & Die roll width \\
$F_{\mathrm{p}}$ & Punch force \\
$R_{\mathrm{m}}$ & Tensile strength \\
$R_{\mathrm{p} 0.2}$ & Yield strength \\
$T_{\mathrm{c}}$ & Cutting temperature \\
\hline
\end{tabular}


Experimental Investigation of Process Forces and Part Quality for Fine Blanking of Stai...

\section{Initial Situation and Motivation}

Stainless steel is crucial for many application fields as an alternative for corrosive applications, showing a growing volume of 3 - 5 \% p.a. [1]. Its non-corroding properties are important e.g. for industries with high hygiene standards such as medical and nutrition industries, but also for applications with aggressive environmental influences such as naval ship building or offshore wind power drives. It is increasingly used in energy and nuclear sector [2]. One of the first developed stainless steels (Krupp Company, Germany, 1912) is up to now amongst the most frequently used stainless steel alloys [3]. It is known under the compositional name X5CrNi18-10 (AISI 304) or the material number 1.4301, which is the first number in the class of stainless steels. The material was formerly known as V2A (short for "Versuchsschmelze 2 Austenitisch", experimental melt 2 austenitic). X5CrNi18-10 is not a high-strength steel per se but becomes difficult to process due to the high hardness of the martensite phase, known as transformation-induced plasticity (TRIP) effect. In general, work hardening is of advantage for using favorable property combinations of ductility and strength, but in the case of $\mathrm{X} 5 \mathrm{CrNi18}-10$, this effect complicates the processing on account of high hardness. Due to the importance of this material, its processability is of utmost importance. Thus, it is desirable to investigate the fine blanking properties of this steel. A large number of investigations have been dedicated to X5CrNi18-10 both in general and focused on forming technology. For instance, BAY investigated the material as part of a tribological system for forming [4]. ERIKSSON and OLSSON conducted research on the galling resistance of X5CrNi18-10 sheet material using pin-on-disc testing [5]. HETZNER ET AL. investigated the local adjustment of tribological properties for so-called sheet bulk metal forming processes especially of X5CrNi18-10 [6]. DANIEL ET AL. did research on the lifetime of PVD coatings of fine blanking punches with X5CrNi18-10 sheet material [7]. NEUGEBAUER ET AL. investigated the influence of a pre-defined load on the precision cutting process of X5CrNi18-10 sheet material [8]. In terms of punching, ARSLAN and ÖZDEMIR presented research on punch wear at punching X5CrNi18-10 [9]. EMONTS investigated punching with laser heating support [10]. Fine blanking faces, due to the different tool concept and process guidance, different parameters and output than punching. A promising approach, however, to mitigate many challenges of the fine blanking process is inductive heating prior to the fine blanking process [11]. The fine blanking of inductively heated X5CrNi18-10 sheet metal has not been subject of systematical research yet, though the process window lies within distinct boundaries [12].

\section{Scientific Problem and Materials}

The objective of this research is the experimental investigation of process forces and part quality for fine blanking of stainless steel with inductive heating. The interactions between metal sheet temperatures in the moment of cutting and process forces are to be investigated as well as the changes of the part quality in terms of dimensional accuracy, die roll and cut surface state.

The elemental composition of $\mathrm{X} 5 \mathrm{CrNi18}-10$ is of utmost importance for fine blanking. The compositional name suggests $0.05 \%$ C, $18 \% \mathrm{Cr}$ and $10 \% \mathrm{Ni}$. In Table 1, the composition of X5CrNi18-10 is given more in detail according to the standard DIN EN 10088-2 [13]. In the previous section, the importance of the elemental composition of X5CrNi18-10 and its consequences for the fine blanking process have been explained. As the elemental composition of the specimens is of high importance, they were investigated using optical emission spectroscopy. The results can be found in Table 1 .

Table 1. Elemental composition of the X5CrNi18-10 specimens determined by optical emission spectroscopy in comparison to the nominal values as defined in the standard DIN EN 10088-2 [13]

\begin{tabular}{lccccccccccc}
\hline Element & $\mathrm{C}$ & $\mathrm{Si}$ & $\mathrm{Mn}$ & $\mathrm{P}$ & $\mathrm{S}$ & $\mathrm{Cr}$ & $\mathrm{Mo}$ & $\mathrm{Ni}$ & $\mathrm{N}$ & $\mathrm{Cu}$ & Others \\
\hline Nominal (max.) & 0.07 & 1.00 & 2.00 & 0.045 & 0.015 & $17.5-19.5$ & - & $8.0-10.5$ & 0.10 & - \\
\hline Specimen & 0.0467 & 0.345 & 1.15 & 0.035 & $<0.001$ & 18.12 & - & 9.16 & 0.0108 & 0.429 & 0.0054 \\
\hline
\end{tabular}


As can be seen in Table 1, the specimens do consist of X5CrNi18-10, correspond to the standard and are suitable for forming as a consequence of the relatively high portion of austenite stabilizing elements $\mathrm{Cu}$ and $\mathrm{Ni}$. It has to be considered that the results of optical emission spectroscopy are in general less accurate than the results of the melt composition analysis. Furthermore, after an annealing process, some elements as Sulfur tend to appear increased in comparison to the melt composition analysis depending on the annealing process, as optical emission spectroscopy only investigates the surface of a specimen. The mechanical properties were tested in tensile tests and were determined as $\mathrm{Rp} 0.2=271 \mathrm{MPa}$ and $\mathrm{Rm}=608 \mathrm{MPa}$.

The importance of the elemental composition as presented in Table 1 lies in the specific properties of X5CrNi18-10. They are unusual for a steel material: corrosion-resistant, non-ferromagnetic and not hardenable by heat treatment [3]. As a metastable austenite, X5CrNi18-10 can turn to martensite when processed with a forming process. This results in a magnetization of the non-ferromagnetic austenite and, more important for the forming process, in a sudden impact on the forming press known as cutting impact. The metal lattice was investigated by means of metallographic cross-sections and is given, together with the SCHAEFFLER diagram for X5CrNi18-10, in Figure 1.
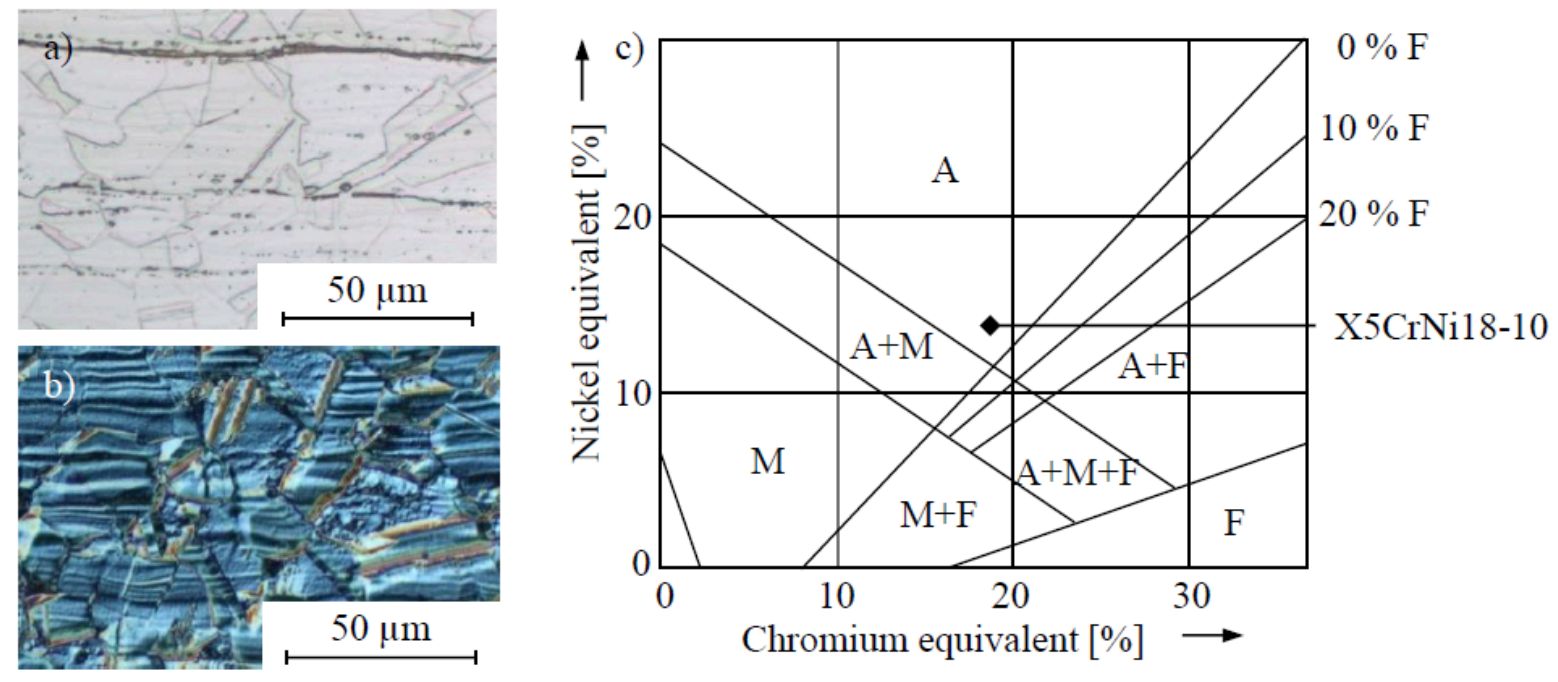

Figure 1. Cross-section of specimens a) with standard and b) with Beraha II-etching and c) SCHAEFFLER diagram with marking point for X5CrNi18-10. A: Austenite, F: Ferrite, M: Martensite [14]

As can be seen in Figure 1, the specimens show an austenitic metal lattice with some anisotropy. The austenite can be recognized by characteristic twin structures in Figure 1a). The Beraha II-etching in Figure 1b) shows austenite in dark and blue colors. The needle-like microstructure of martensitic parts can not be found in the cross-sections. The anisotropy in horizontal direction is due to the hot rolling process in which the sheet metal was produced prior to the experiments.

The stability of austenite depends strongly on the portion of nickel equivalents in the X5CrNi18-10 alloy, visible in the SCHAEFFLER diagram in Figure 1c). Austenite stabilizing elements are $\mathrm{Cu}, \mathrm{Ni}, \mathrm{Co}$, and $\mathrm{Mn}$ [15]. As a consequence, the bigger the portions of those elements are in the X5CrNi18-10 alloy (within the limits of the standard), the better it can be formed and especially fine blanked, as the risk of turning into martensite diminishes. In conclusion, the specimens are well apt for fine blanking experiments. Cutting impact is not expected to a greater extend, as the peril of martensitization is comparatively low and not enforced by the servomechanical press. 
Experimental Investigation of Process Forces and Part Quality for Fine Blanking of Stai...

\section{Approach}

In order to meet the objective of this research, the experiments were performed following the process route of inductive heating and subsequent fine blanking of prepared specimens which has already been described [10]. Due to the specific properties of $\mathrm{X} 5 \mathrm{CrNi18}-10$, oxidation effects as they do often accompany inductive heating are not expected [16]. The experiments were performed using an iew TTH25 inductive heating device and a servo mechanical Feintool XFT 2500speed servo mechanical fine blanking press at a cutting velocity vc $=50 \mathrm{~mm} / \mathrm{s}$. In every experiment, a specimen was heated using the induction heating device, then transferred to the fine blanking press and fine blanking was performed. The temperature measurement included two pyrometers of type Sirius SI23 controlling the inductive heating device. The temperature changes during the experiments were recorded using a thermocouple fixed to each specimen. The heating process is presented in Figure 2.
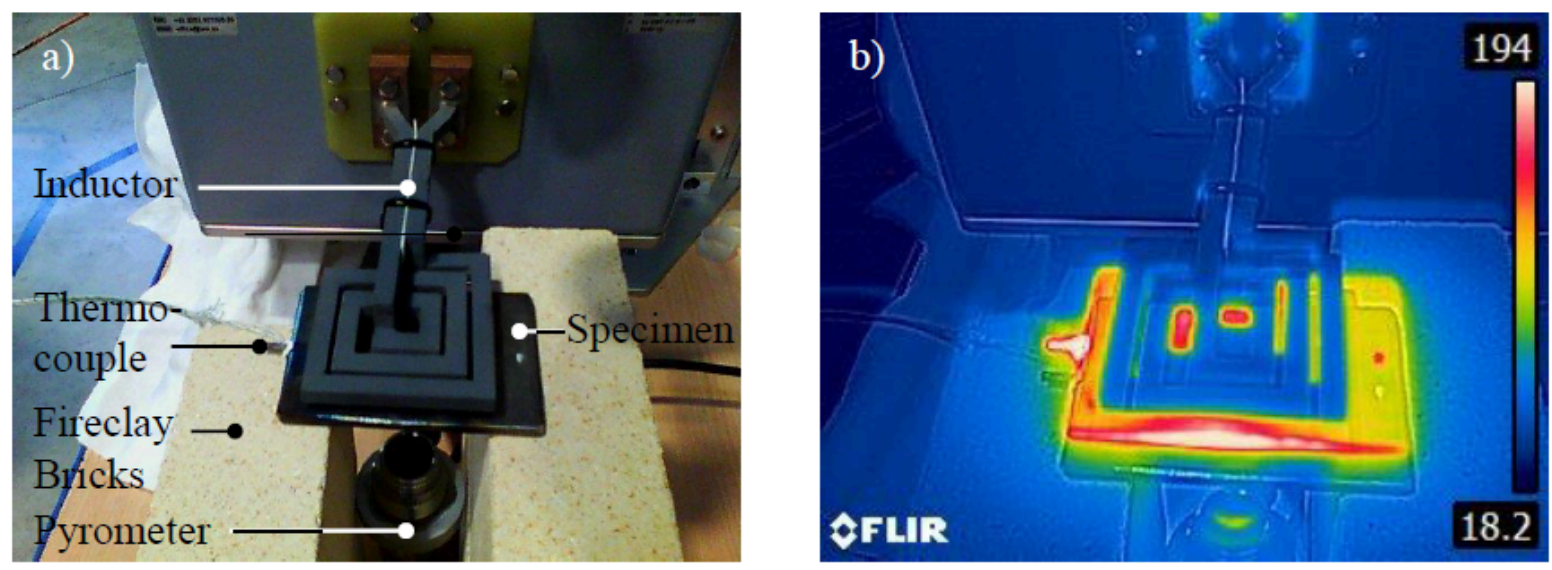

Figure 2. Inductive heating a) in standard photography and b) in thermal imaging photography with unit ${ }^{\circ} \mathrm{C}$

Six different target temperatures between $150{ }^{\circ} \mathrm{C}$ and $400{ }^{\circ} \mathrm{C}$ in steps of $50{ }^{\circ} \mathrm{C}$ each have been investigated, enhanced by reference experiments at room temperature without heating, starting at low temperatures and increasing the temperature step by step. The upper boundary of $400{ }^{\circ} \mathrm{C}$ was chosen in order to safely remain below the recrystallization temperature which is expected around $560{ }^{\circ} \mathrm{C}$ for $\mathrm{X} 5 \mathrm{CrNi18}-10$. At those temperatures, no recrystallization effects are to be expected [17]. The sheet thickness was $\mathrm{s}=6 \mathrm{~mm}$. All experiments have been repeated four times. The process forces have been measured as well as the temperatures. An experimental geometry "arrow part" was used which is specially designed for fine blanking experiments. The quality properties of the fine blanked parts have been measured according to the standard VDI 2906 [18]. This is depicted in Figure 3. 
a)

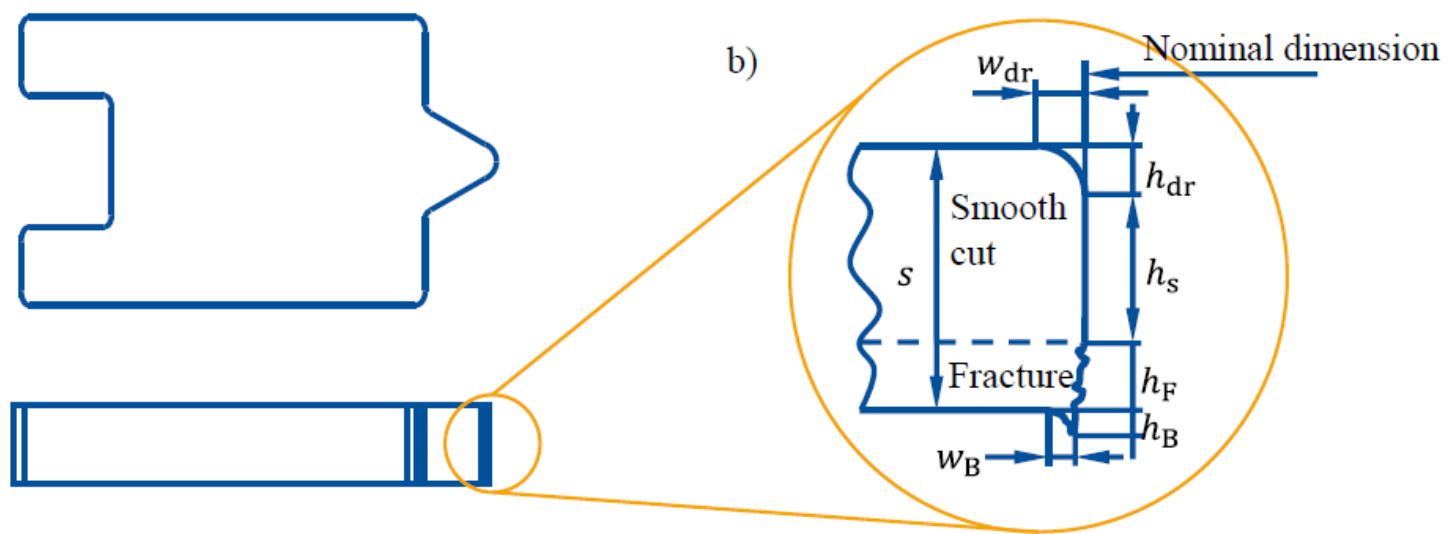

Figure 3. "Arrow part" geometry a) with quality properties b) according to the standard VDI 2906 [18]

A twofold falling fine blanking layout was used. This layout can be implemented in continuous experimentation or in single-stroke experiments, as it was for this paper. Twofold falling experiments provide the advantage that more parts are available especially for destroying analysis methods and thusly extend the data basis. The fine blanking layout is shown in Figure 4.

a)

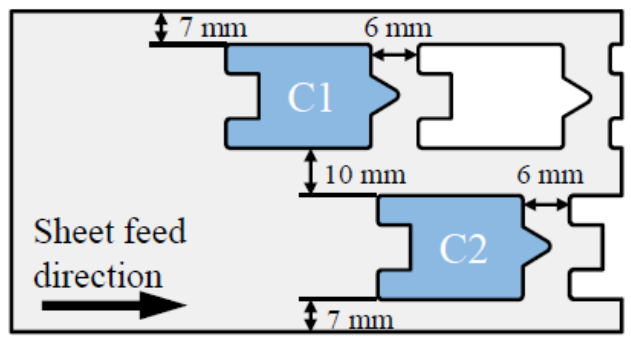

b)

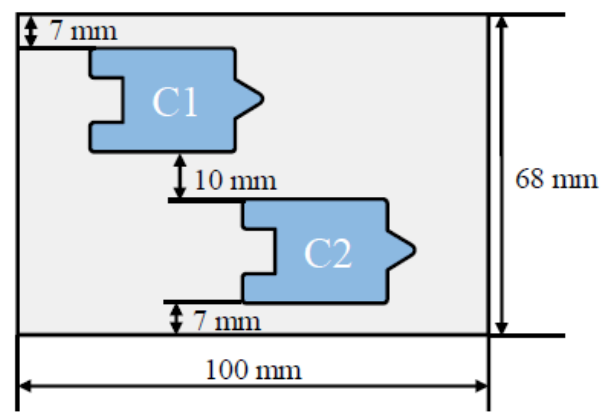

Figure 4. Twofold fine-blanking layout "arrow part" for continuous experiments a) and for single-stroke experiments b), which was used for this paper. The fine blanking cavities are referred to as C1 for the rear left cavity and C2 for the right front cavity

As can be seen in Figure 4, the fine blanking layout does provide enough clearance between the cavities to ensure that there is but little mutual influencing between the fine blanking cavities [19]. All experiments have been performed using the same set of tool elements, i.e. punch, blank holder, counter punch, and guide plate. The tool concept is presented in Figure 5. 


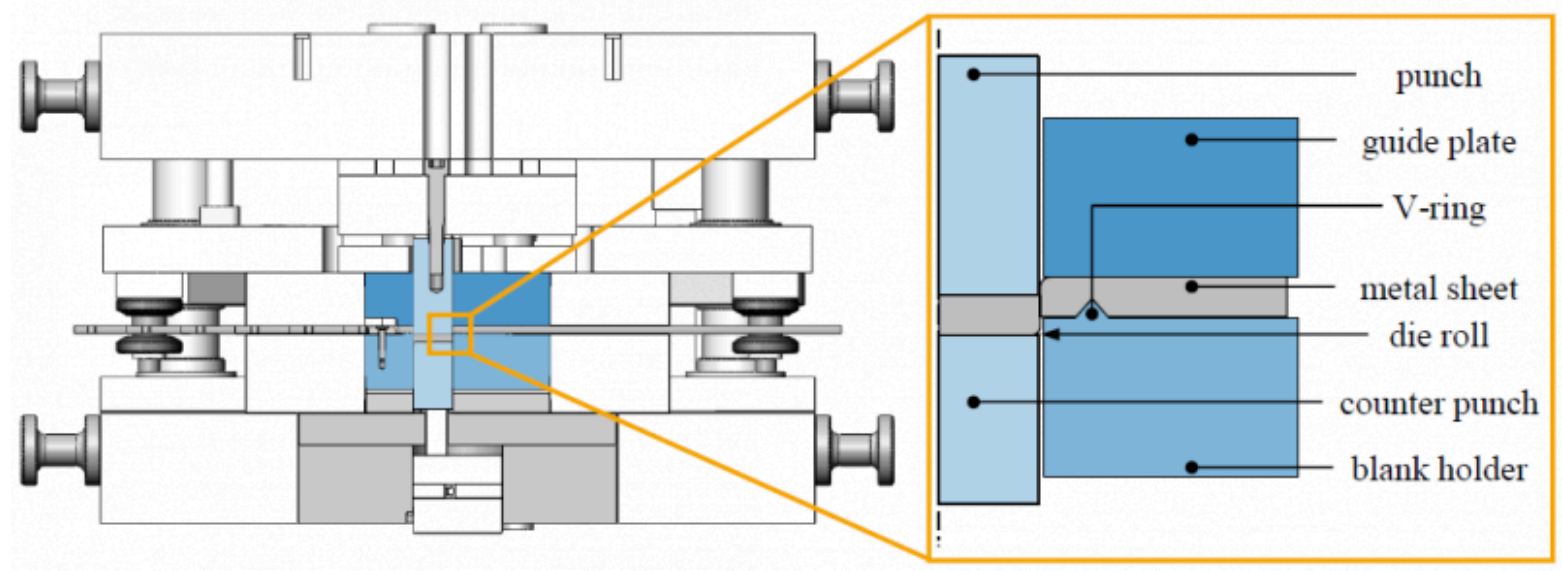

Figure 5. Fine blanking tool with detail presentation of active elements and die roll

As can be seen in Figure 5, the tool concept used a standard fine blanking setup consisting of punches, guide plate, counter punches and blank holder. A circumferential V-ring with three gaps was adapted to the blank holder at both cavities.

\section{Results}

During the experiments, the process forces were measured as a main objective for fine blanking lies in the reduction of process forces with the aim to process high-strength steels in a reliable way. Results for one stroke at cutting temperature $\mathrm{T}_{\mathrm{C}}=24^{\circ} \mathrm{C}$ and $\mathrm{T}_{\mathrm{C}}=377^{\circ} \mathrm{C}$ are given in Figure 6.

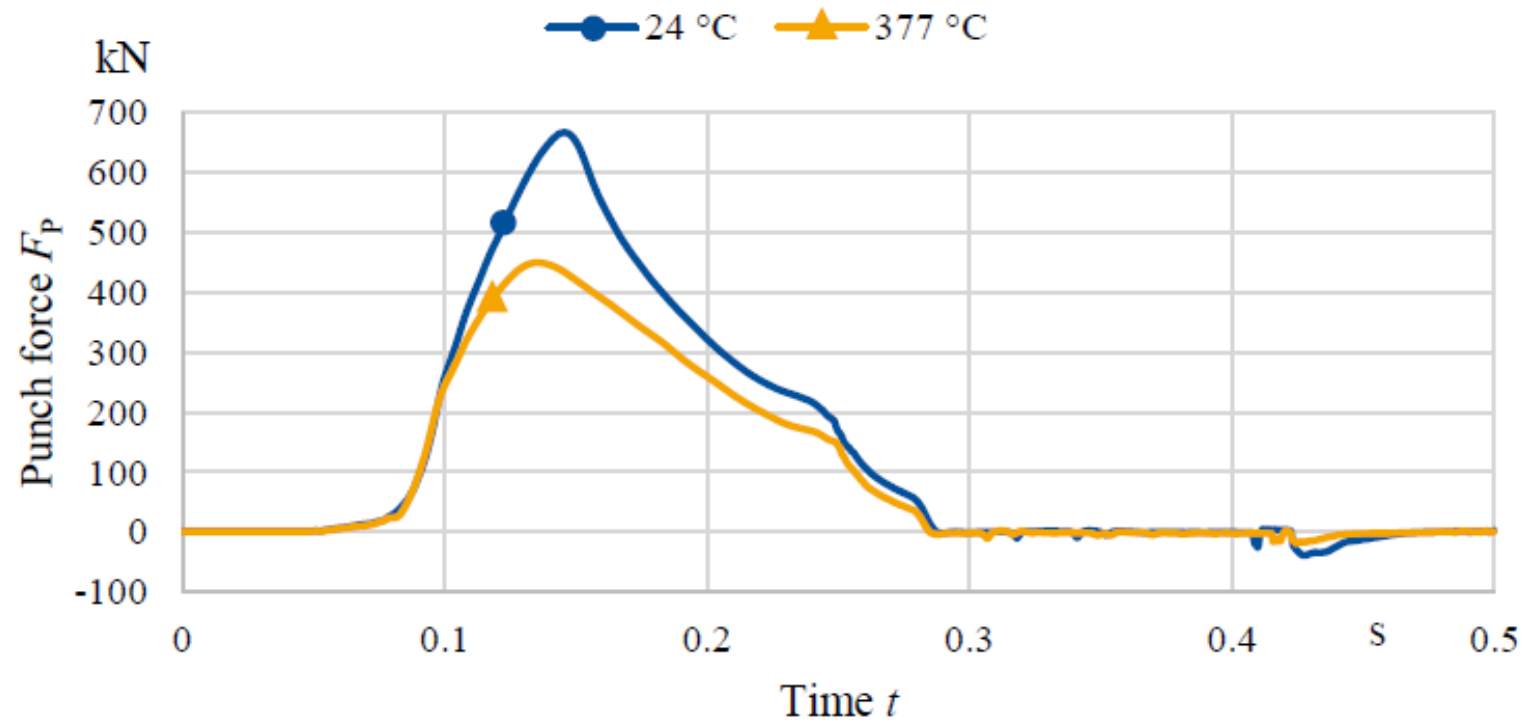

Figure 6. Punch force curve at cutting temperature $\mathrm{T}_{\mathrm{c}}=24^{\circ} \mathrm{C}$ and $\mathrm{T}_{\mathrm{c}}=377^{\circ} \mathrm{C}$

In Figure 6, several observations can be made. Firstly, the punch forces are reduced at higher cutting temperature. The maximum punch force is diminished by $33 \%$ in comparison to fine blanking at room temperature. Secondly, the course of the punch force is at a higher temperature more homogenous. In general, the punch force shows different 
sections: closing of the tool (growing punch force), start of cutting (maximum point), cutting (decreasing force, due to the falling cutting resistance as a result of the increasingly thin remaining sheet metal at the cutting line) breaking of the burr (small peak) and subsequent power drop to zero. Hence, the observation is that the punch force shows a more homogenous course during the cutting. For a better understanding, the punch force maxima of all experiments are presented in Figure 7.

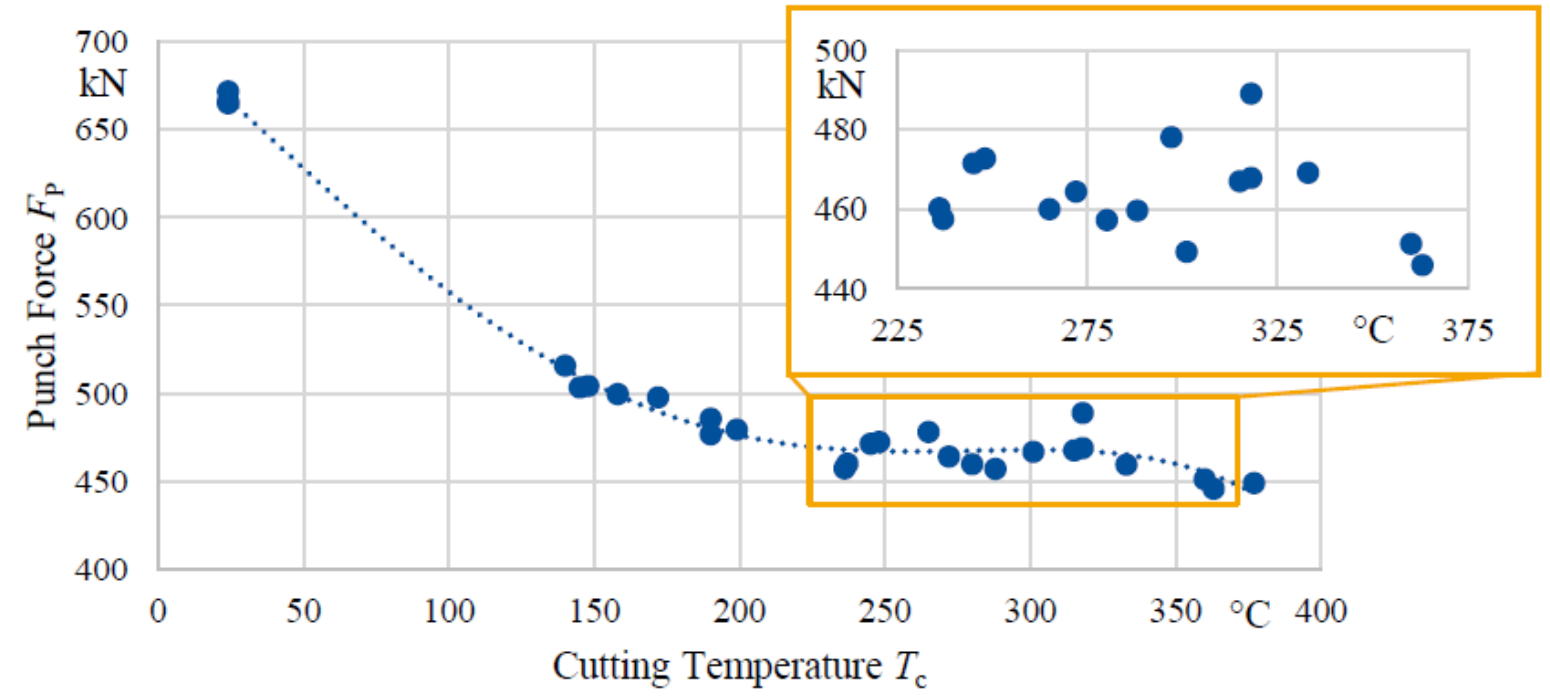

Figure 7. Punch force maxima at different cutting temperatures with polynomic approximation function of $4^{\text {th }}$ grade

The development of the punch force maxima as depicted in Figure 7 shows some noticeabilities. Firstly, the punch force maxima do indeed decrease with growing cutting temperature. Secondly, the decrease is considerable and amounts to $33 \%$ lower values at a cutting temperature $\mathrm{T}_{\mathrm{c}}=377^{\circ} \mathrm{C}$ compared to the room temperature reference. Thirdly, the decrease is not linear, as would be suggested by the temperature terms in JOHNSON-COOK flow stress model [20]. Instead, it shows an asymptotic decrease with a second peak between $\mathrm{T}_{\mathrm{C}}=250{ }^{\circ} \mathrm{C}$ and $\mathrm{T}_{\mathrm{C}}=350{ }^{\circ} \mathrm{C}$. In addition to the process forces, the part quality in terms of dimensional accuracy, die roll, and cut surface state was measured. The first focus of investigation was the macro geometric dimensional accuracy. The results are shown in Figure 8. 
Legend: $\Delta$ rear left cavity $\quad$ front right cavity

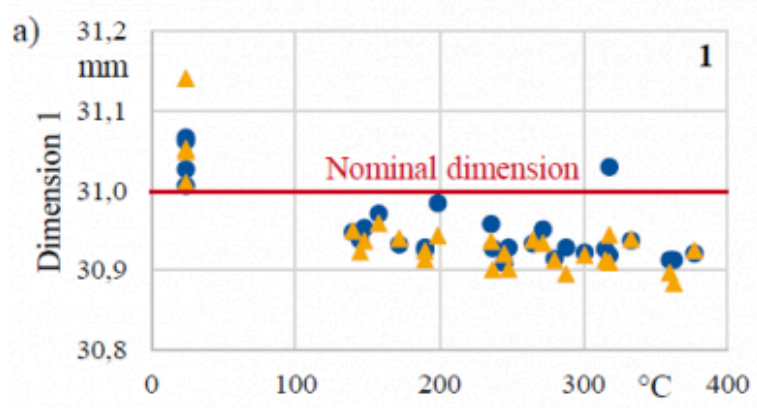

Cutting Temperature $T_{\mathrm{c}}$

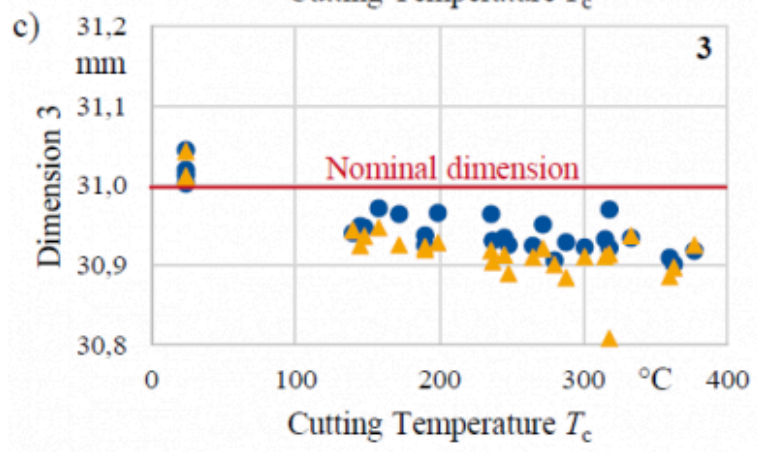

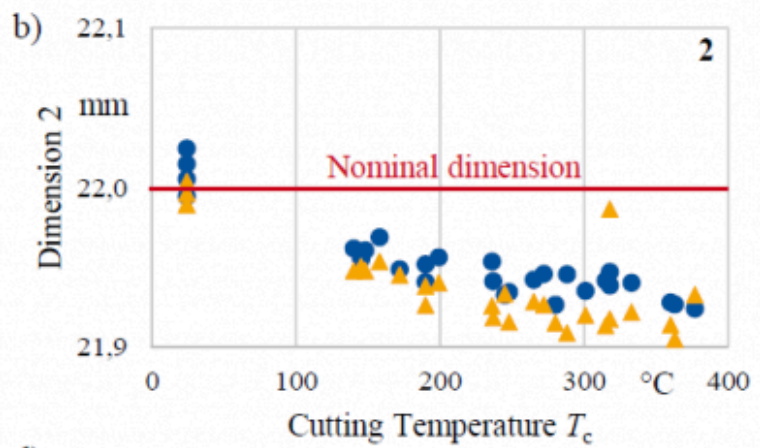

d)

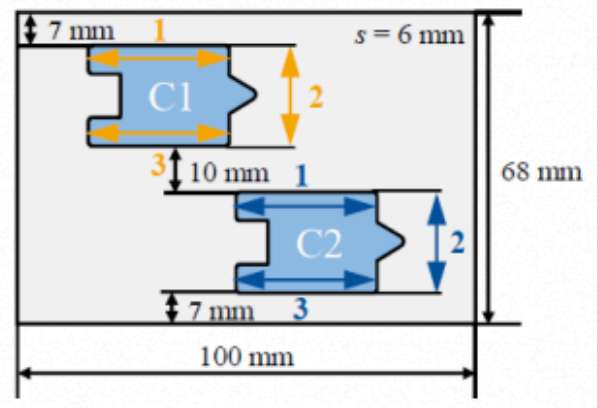

Figure 8. Macroscopic dimensional accuracy, measured at three points and on the two cavities: Dimension 1 - length a), Dimension 2 - width b), Dimension 3 - length, on the opposite side c), and fine blanking layout with visualization of the measuring points $\mathrm{d}$ )

As can be seen in Figure 8, the reference experiments at room temperature generate dimensions slightly above the nominal values. With increasing cutting temperature, the dimensions decrease. In this case, there is no obvious reason to suggest non-linear behavior. In consequence, the values show thermal shrinking, which will, in absence of a justified better assumption, be considered linear. A very important value for assessing fine blanking processes is the die roll [21]. It was measured at the fine blanked specimens using an optical method of structured-light 3D scanning with subsequent comparison to the nominal contour described by VOIGTS ET AL. [22]. The results are given in Figure 9.

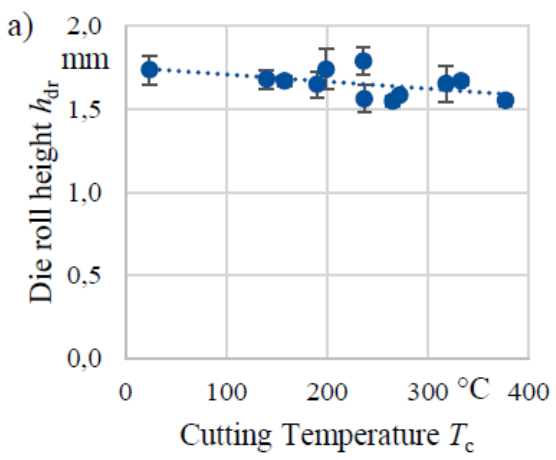

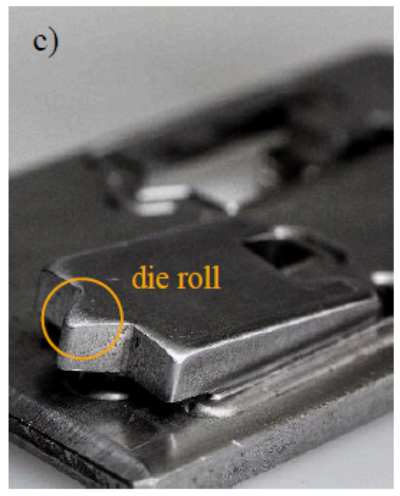

Figure 9. Die roll height hdr a), die roll width wdr b) of the fine blanked specimens, with a photography (@Tobias Kaufmann, WZL) with die roll marking c) 
As can be seen in Figure 9, the die roll slightly diminishes with increasing cutting temperature. As a low die roll is a significant quality requirement, heating prior to the fine blanking indicates in this case an increase in part quality. As a last point, the state of the cut surface was investigated using tactile topography measuring and light microscopy imaging. Exemplary results are given in Figure 10.
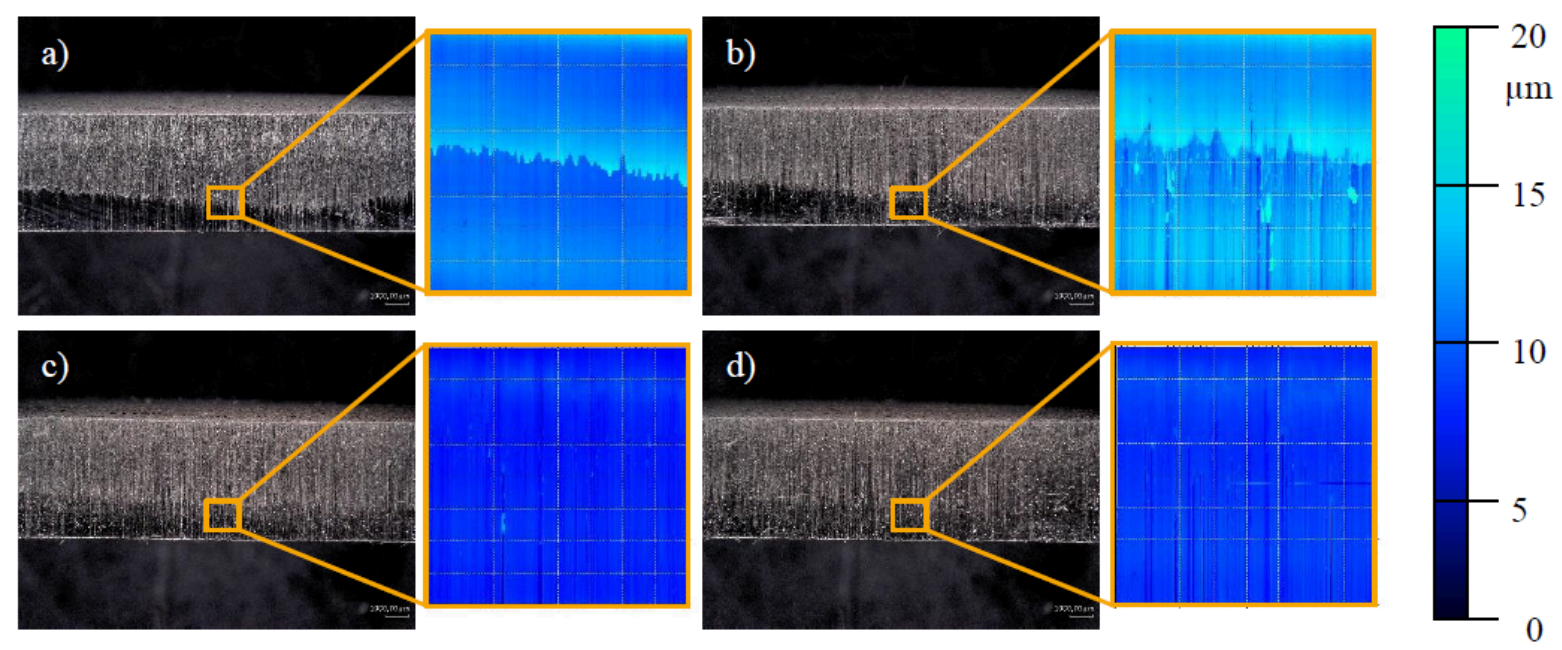

Figure 10. Light microscopy images of the cut surface (left) and topography measurement (right) at specimens with cutting Temperatures a) $\left.\mathrm{T}_{\mathrm{c}}=24^{\circ} \mathrm{C}, \mathrm{b}\right) \mathrm{T}_{\mathrm{c}}=199^{\circ} \mathrm{C}, \mathrm{c}$ ) $\mathrm{T}_{\mathrm{c}}=288^{\circ} \mathrm{C}$, and d) $\mathrm{T}_{\mathrm{C}}=377^{\circ} \mathrm{C}$

As can be seen in Figure 10, the cut surface of the specimens, although it shows in each case a smooth cut portion of $100 \%$, is slightly different. What can be seen as a color change in the light microscopy images turns out to be a burr on the surface in a dimension of up to approx. $10 \mu \mathrm{m}$ height. This phenomenon decreases with growing cutting temperature.

\section{Discussion}

As described in the previous section, the first observation gained from the experiments is a significant decrease of fine blanking punch forces with increasing cutting temperatures. This is not surprising, as the effect of decreasing mechanical strength with increasing temperatures is well known for steels and e.g. stated by DEHGHAN-MANSHADI ET AL. [24] and KIM and YOO [24] for X5CrNi18-10. However, the decrease does not behave linearly. This indicates that flow models as JOHNSON-COOK do not suffice for a consideration of fine blanking with inductive heating. This was already stated by LIAN ET AL. [25] and can be supported by the results of the experiments performed here. The non-typical behavior of the values of maximum punch force between $\mathrm{T}_{\mathrm{C}}=250{ }^{\circ} \mathrm{C}$ and $\mathrm{T}_{\mathrm{C}}=350{ }^{\circ} \mathrm{C}$ can be explained by dynamic strain aging mechanisms. As CHO, YOO and JONAS found out, dynamic strain aging occurs in X5CrNi18-10 primarly between $900{ }^{\circ} \mathrm{C}$ and $1,100{ }^{\circ} \mathrm{C}$ due to the substitional elements $\mathrm{Cr}$ and Ni. Strain aging due to the interstitial elements $\mathrm{C}$ and $\mathrm{N}$ can, however, occur between $150{ }^{\circ} \mathrm{C}$ and $300{ }^{\circ} \mathrm{C}$ [26]. NIKITIN stated that a temperature increase of $50{ }^{\circ} \mathrm{C}$ suppresses the forming induced martensite formation. Furthermore, he found out that between $200{ }^{\circ} \mathrm{C}$ and 500 ${ }^{\circ} \mathrm{C}$ dynamic and static strain aging can occur and stabilize the dislocation structures, activating diffunding atoms of $\mathrm{Cr}$ above $400{ }^{\circ} \mathrm{C}[27]$.

The part quality increased due to inductive heating. Linear shrinking due to heating has to be taken into account but can be controlled by constructive measures according to PETERLI [28]. Decreasing die roll and decreasing roughness of the cut surface are advantageous in terms of product qualities of fine blanked parts. Furthermore, a general heating of sheet metal minimizes fluctuations of the process temperatures and contributes to reliable and predictable process 
guidance.

\section{Conclusion and Outlook}

In conclusion, the following can be stated. Inductive heating of stainless steel sheet metal prior to fine blanking is of advantage. It lowers the process forces and improves part quality as well as process reliability. In the special case of metastable austenitic steel, martensitization can be suppressed by heating. In total, inductive heating prior to fine blanking is a promising approach, which should be investigated further, including more classes of sheet metal.

\section{Acknowledgements}

The authors want to thank the German Research Foundation (Deutsche Forschungsgemeinschaft DFG) for the funding of the research work within the project "Erforschung der thermomechanischen Wechselwirkungen in der Scherzone beim Feinschneiden von höherfesten erwärmten Blechwerkstoffen" (KL 500/182-1) and the project " Erforschung der Wechselwirkungen von einer inkrementellen Randzonenumformung und einer HPPMS-Beschichtung auf Feinschneidstempeln zur Ermöglichung einer belastungsgerechten Einstellung der Oberflächenintegrität" (BE 2542/14-1). Special thanks go to Andreas Peters for his kind willingness to discuss metal-material relations, to Marcel Botz for his diligent support during the execution of the experiments, to Mario Kittel for the preparation of the crosssections, to Tobias Kaufmann for the photography in Fig. 8 and to Mirco Trosin and Matthias Marx for the accurate measuring of the specimens.

\section{Bibliography}

[1] Schneider, M.; Liewald, M.: Characterization of the austenitic stability of metastable austenitic stainless steel with regard to its formability. In: AIP Conference Proceedings 1960, Vol.1, 2018

[2] Venkatraman, M.; Pavitra, K.; Jana, V.; Kachwala, T.: Manufacturing and critical applications of stainless steel - An Overview. In: Advanced Materials Research Vol. 794, 2013, pp. 163-173

[3] Cobb, H.M.: The History of Stainless Steel. ASM International, 2010

[4] Bay, N.O.: Tribo-systems for Sheet Metal Forming. In: Metallurgiske Processer I Danmark: Proceed. Dansk Metallurgisk Selskabs Vintermøde, 2009, pp. 160-175

[5] Eriksson, J.; Olsson, M.: Evaluation of galling resistance for some selected combinations of tool steels / stainless steel sheet materials / lubricants using pin-on-disc testing. In: NordTrib, Storforsen, 2010

[6] Hetzner, H.; Koch, J.; Tremmel, S.; Wartzack, S.; Merklein, M.: Improved Sheet Bulk Metal Forming Processes by Local Adjustment of Tribological Properties. In: J. Manuf. Sci. Eng. 133(6), 2011

[7] Daniel, J.; Žemlička, R.; Grossman, J.; Lümkemann, A.; Tapp, P.; Galamand, C.; Fořt, T.: Comparison of Lifetime of the PVD Coatings in Laboratory Dynamic Impact Test and Industrial Fine Blanking Process. In: Materials 19 (9), 2020

[8] Neugebauer, R.; Kräusel, V.; Barthel, T.; Jesche, F.; Schönherr, J.: Influence of a defined pre-load on the stress-state in the precision cutting process. In: CIRP Annals - Manufacturing Technology 62, 2013, pp. 271-274

[9] Arslan, Y.; Özdemir, A.: Punch structure, punch wear and cut profiles of AISI 304 stainless steel sheet blanks manufactured using cryogenically treated AISI D3 tool punches. In: Int J Adv Manuf Technol, 2016, 87:587-599

[10] Emonts, M.: Laserunterstütztes Scherschneiden von hochfesten Blechwerkstoffen. Doctoral thesis, RWTH Aachen 
University, 2010

[11] Weiser, I.F., Mannens, R., Feuerhack, A., Trauth, D., Bergs, T.: An analytical approach for the determination of the temperature distribution in the cross section of a sheet metal caused by inductive heating. In: Procedia Manufacturing 29, 2019, pp. 353-360

[12] Wesner, T.: Virtuelle und experimentelle Methoden zur Voraussage des Prozessfensters beim Feinschneiden. Doctoral thesis, ETH Zürich, 2017

[13] DIN EN 10088-2: Stainless steels - Part 2: Technical delivery conditions for sheet/plate and strip of corrosion reisting steels for general purposes. DIN Deutsches Institut für Normung e.V., 2014

[14] Guiraldenq, P.; Hardouin Duparc, O.: The genesis of the Schaeffler diagram in the history of stainless steel. In: Metall. Res. Technol. 114, 613, 2017

[15] Milititsky, M.; De Wispelaere, N.; Petrov, R.; Ramos, J.E.; Reguly, A.; Hänninen, H.: Characterization of the mechanical properties of low-nickel austenitic stainless steels. In: Materials Science and Engineering A 498, 2008, pp. $289-295$ [16] Weiser, I.F.; Hild, R.; Feuerhack, A.; Trauth, D.; Bergs, T.: Experimental investigation of Oxide Layer Formation Depending on Temperature Holding Time during Inductive Heating of Annealed 16MnCr5. In: Procedia Manufacturing 47, 2020, pp. $1328-1333$

[17] El Wahabi, M.; Cabrera, J.M.; Prado, J.M.: Hot working of two AISI 304 steels: a comparative study. In: Materials Science and Engineering A343, 2003, pp. 116-125

[18] VDI 2906: Quality of cut faces of (sheet) metal parts after cutting, blanking, trimming or piercing. VDI standard, 1994

[19] Voigts, H.; Trauth, D.; Feuerhack, A.; Mattfeld, P.; Klocke, F.: Dependencies of the die-roll height during fine blanking of case hardening steel 16MnCr5 without V-ring using a nesting strategy. In: Int J Adv Manuf Technol, 2018, 95:3083-3091 [20] Johnson, G.H.; Cook, W.H.: Fracture characteristics of three metals subjected to various strains, strain rates, temperatures, temperatures and pressures. In: Engineering Fracture Mechanics Vol. 21, No. 1, 1985, pp. 31-48

[21] Stanke, J.; Feuerhack, A.; Trauth, D.; Mattfeld, P.; Klocke, F.: A predictive model for die roll height in fine blanking using machine learning methods. In: Procedia manufacturing 15, 2018, pp. 570-577

[22] Voigts, H.; Hild, R.; Feuerhack, A.; Bergs, T.: Echtzeit-Bauteilprüfung beim Feinschneiden. In: wt WerkstattsTechnik online 6, 2020

[23] Dehghan-Manshadi, A.; Barnett, M.R.; Hodgson, P.D.: Recrystallization in AISI 304 austenitic stainless steel during and after hot deformation. In: Materials Science and Engineering A 485, 2008, pp. 664-672

[24] Kim, S.; Yoo, Y.: Dynamic recrystallization behavior of AISI 304 stainless steel. In: Materials Science and Engineering A311, 2001, pp. 108-113

[25] Lian, J.; Liu, W.; Sparrer, Y.; Shen, F.; Münstermann, S.: Temperature Dependence of Plastic Flow, Anisotropy and Ductile Fracture. In: Procedia Manufacturing 47, 2020, pp. 1308-1313

[26] Cho, S.H.; Yoo, Y.C.; Jonas, J.J.: Static and dynamic strain aging in 304 austenitic stainless steel at elevated temperatures. In: Journal of materials Science letters 19, 2000, pp. 2019-2022

[27] Nikitin, I.: Zur Verbesserung des Ermüdungsverhaltens des austenitischen Stahls X5CrNi18-10 im 
Experimental Investigation of Process Forces and Part Quality for Fine Blanking of Stai...

Temperaturbereich $25-600^{\circ} \mathrm{C}$ durch mechanische Randschichtverfestigungsverfahren. Doctoral thesis, Universität Kassel, 2007

[28] Peterli, M.: Heat Treatment Simulation and Experimental Investigation of Thermal Distortion with a Special Focus on Fineblanked Parts. Doctoral thesis, ETH Zürich, 2017

PDF automatically generated on 2021-05-19 09:28:49

Article url: https://popups.uliege.be/esaform21/index.php?id=2575

published by ULiège Library in Open Access under the terms and conditions of the CC-BY License

(https://creativecommons.org/licenses/by/4.0) 